\section{Parliamentary Secretary to the Minister for Science}

IN moving the second reading of the Ministers of the Crown (Parliamentary Secretaries) Bill in the House of Lords on December 8, the Minister for Science, Lord Hailsham, referred to the clause which permitted the appointment of a Parliamentary Secretary to the Minister for Science (see also Nature, December 3, p. 782). He said that the arrangement under which questions relating to responsibilities of the Minister for Science were answered by somo six or seven different spokesmen in the House of Commons was neither popular in that House nor convenient to him. It frustrated what he thought was a main advantage in appointing a Minister for Science, namely, the production of an image of scientific policy as a consistent whole. A collection of spokesmen, however skilful, could not answer supplementary questions in the same way as someone in the Department who knew the mind of the Minister, and there was much background which could not be conveyed in the ordinary brief. He thought that the present practice prevented the building up and presentation as a whole of a coherent body of doctrine about the work of the Department. Lord Hailsham did not accept the view that the Minister for Science should necessarily be in the House of Commons. $\mathrm{He}$ thought there were advantages in the Minister being in the House of Lords, which might even be the ideal position; but he suggested that the Prime Minister is entitled to some latitude in this respect, and in this view Lord Alexander of Hillsborough, speaking for the Opposition, concurred.

\section{Termites in the Humid Tropics}

A symposium on "Termites in the Humid Tropics", organized jointly by Unesco and the Zoological Survey of India, was held in New Delhi during October 4-12 under the presidency of Dr. M. I. Roonwal, director of the Zoological Survey. Among the eighty-four registered participants were delegates from Burma, Ceylon, Indonesia, Pakistan and Thailand. In addition, Prof. A. E. Emerson (University of Chicago), Prof. M. S. Ghilarov (Academy of Sciences, Moscow), Prof. K. Gösswald (University of Würzburg) and W. V. Harris (Commonwealth Institute of Entomology, London) attended as guests of Unesco.

Some forty papors were submitted, the majority of which were read and discussed at one or other of the six sections-systematics and morphology, physiology and development, general biology, ecology, intestinal symbionts and termite control. Current research in India provided the basis for many of the communications. An interesting series of papers was contributed by workers at the Defonco Research Laboratories, Kanpur, covering the laboratory culture of Odontotermes for testing purposes, the ecology of fungus gardens constructod by this genus, and the relative susceptibility of local timbers to termites. The development of the Odonto. termes redemanni embryo was dealt with by $\mathrm{D}$. Mukerji in a beautifully illustrated paper. Other communications dealt with regressive evolution among tormites (A. E. Emerson), the termite fauna of the U.S.S.R. (M. S. Ghilarov), termites in relation to Indian agriculture (D. B. Reddy and T. Sankaran), a portable plant for termite-proofing timber, bamboo and thateh used for low-cost buildings (V. R. Sonti), to mention only a few. It is understood that the proceedings of the symposium will be published in due course by Unesco.

At the final plenary sossion a resolution was passed recommending to the consideration of Unesco the appointment of an International Termite Commission to undertake, among other things, the co-ordination of testing techniques for termite-proof materials, the study of the problem of accidental introduction of injurious termites, and the collection of information on termites as pests of growing crops and methods of control. A field excursion to the Forest Research Institute, Dehra Dun, provided a welcome break in a well-organized, but rather concentrated, programme of meetings, public lectures and broadcasts.

Trinidad and Tobago Coconut Research, Ltd.

THE new Research Station situated at Champs Fleurs, Trinidad, West Indies, is an institution intended to foster research relative to coconuts. It is administered by the Directors of Trinidad and Tobago Coconut Research, Ltd., which is a non-profit making company financed jointly by West Indian Oil Industries, Ltd., Trinidad Manufacturing and Refining Co., Ltd., and the Coconut Growers' Association. The Station will be concerned with all problems pertinent to the cultivation of coconuts, with the ultimate object of increasing copra production at a decreased cost. The Station stands in the West Indian Oil Industries Compound and comprisos a well-equipped laboratory, offices and stores. Relevant scientific periodicals and t9xt-books will be collected to form the nucleus of a library to be located in the main building. The depredation of the destructive red ring disease of coconuts will compel the research team to devote most of its energies to this problem, but, as time permits, attention will bo paid to other problems. It is hoped to study the insect pests of coconuts with special reference to their role as vectors of red ring disease : in this context particular attention will be paid to the coconut palm weevil (Rhyncophorus palmarum), and means of controlling this pest will be sougit. The nutrition of palms will be investigated, again in relation to red ring, but it is hoped that the results of this work will also help in the framing of general recommendations for manuring programmes. Up-to-date summaries of literature on any coconut problems which appear to be causing concern in different parts of the territory will be circulated and it is thus hoped to keep the planting community informed of the results of research into this valuable crop.

\section{Resistant Strains of Micro-organisms}

$\mathrm{IT}_{\mathbf{T}}$ is to be expected, and accepted, that microorganisms inhabiting the gut of animals in the presence of antibacterial substances, such as antibiotics, will be either naturally or developmentally resistant to those substances. It is neither to be expected nor accepted that this state of affairs is necessarily undesirable or such resistant strains necessarily of enhanced pathogenicity or virulence; indeed, the evidence of animal well-being on antibiotic-supplemented diets is overwhelmingly to the contrary. However, caution is justifiable, despito the continuing lack of advorse practical or experimental data in the veterinary field, being engendered to a considerable extent by experience in human medicine with resistant Staphylococci; here, though, both environment and dosage-levels are very different. A recent communication in Nature $(187,288 ; 1960)$ described the isolation by Williams Smith and Crabb 